\title{
Clinical Results of Resection Arthrodesis by Triangular External Fixation for Posttraumatic Arthrosis of the ANKLE JOINT IN 89 CASES
}

\author{
J. Kiene ${ }^{1}$, A. P. Schulz ${ }^{1,2}$, S. Hillbricht ${ }^{1}$, Ch. Jürgens ${ }^{1,2}$, A. Paech ${ }^{1}$ \\ ${ }^{1}$ University Hospital Luebeck, ${ }^{2}$ BG Trauma Hospital Hamburg, Germany
}

\begin{abstract}
The methods for ankle arthrodesis differ significantly, probably a sign that no method is clearly superior to others. In the last ten years there is a clear favour toward internal fixation. We retrospectively evaluate the technique and evaluate the clinical long term results of external fixation in a triangular frame.

Patients and Methods: From 1994 to 2001 a consecutive series of 95 patients with end stage arthritis of the ankle joint were treated. Retrospectively the case notes were evaluated regarding trauma history, medical complaints, further injuries and illnesses, walking and pain status and occupational issues and the clinical examination before arthrodesis. Mean age at the index procedure was 45.4 years (18-82), 67 patients were male (70.5\%). Via a bilateral approach the malleoli and the joint surfaces were resected. An AO fixator was applied with two Steinmann-nails inserted with approximately $8 \mathrm{~cm}$ distance in the distal tibia, one in the neck of the talus and one in the dorsal calcaneus. The fixator was removed after approximately 12 weeks. Follow up examination at mean 4.4 years included a standardised questionnaire and a clinical examination including the criteria of the AOFAS-Score and radiographs. Results: Due to different complications, $8(8.9 \%)$ further surgical procedures were necessary including 1 below knee amputation. In 4 patients a non-union of the ankle arthrodesis developed (4.5\%). The mean AOFAS score improved from 20.8 to 69.3 points.

Conclusion: Non-union rates and clinical results of arthrodesis by triangular external fixation of the ankle joint do not differ to internal fixation methods. The complication rate and the reduced patient comfort reserve this method mainly for infected arthritis and complicated soft tissue situations.
\end{abstract}

\section{INTRODUCTION}

Most authors see the arthrodesis of the ankle joint as the most feasible measure for posttraumatic arthritis of the ankle joint were conservative measures failed, especially as the joint conserving with total ankle arthroplasty cannot achieve equel functional mediumand long term results $[1,30,34,38]$. The methods for ankle arthrodesis differ significantly, probably a sign that no method is clearly superior to others. In the last ten years there is a clear favour toward internal fixa- tion by screws with or without resection of the joint surfaces [23, 25, 33, 37, 42]. Some authors report arthroscopic methods in specific cases [39, 41]. The preference for internal fixation is often based on the gained comfort and compliance of the patients. On the other hand some authors quote a higher rate of non-union for the use of external fixators $[4,8,14,16$, $24,35]$. Often the results of internal fixation are compared with historical studies or techniques using the Charnley-type external fixation with, compared to modern fixators [5], unstable frame fixator constructions $[24,40]$. Studies directly comparing the technique were unable to find a significant difference in non union rates $[6,9,13]$.

This was reason for us the retrospectively evaluate the technique and evaluate the clinical long term results.

\section{Patients}

From 1994 to 2001 a consecutive series of 95 patients with end stage arthritis of the ankle joint were treated. Retrospectively the case notes were evaluated regarding trauma history, medical complaints, further injuries and illnesses, walking, pain status, occupational issues and the clinical examination before arthrodesis.

Mean age at the index procedure was 45.4 years [1882], 67 patients were male $(70.5 \%)$. In all cases the arthritic deformity was due to a posttraumatic condition. The index procedure took place on average 129 months (6-516 months) after trauma. The body mass index (BMI) was mean $27.2 \mathrm{~kg} / \mathrm{m}^{2}$.

Preoperatively 43 patients had a relevant mal-alignment ( 28 with isolated with a pes equinus $\geq 10^{\circ}, 15$ complex deformities with varus-or valgus component $\geq 10^{\circ}$ ). In 41 patients the range of motion (ROM) was decreased with a remaining $\mathrm{ROM}$ of $\leq 20^{\circ}$, in further 37 cases the remaining ROM was $\leq 10^{\circ}$ ROM. 6 patients had developed a non-union after a previous attempt of ankle fusion (twice K-wires, 4 cannulated screws, one with a locked plate). Eight patients had an ipsilateral motoric peroneal lesion, in 11 patients we saw arthritis of hip or knee of the ipsilateral and in 9 cases of the contra-lateral limb. One patient had an amputation of the lower leg due to trauma, one patient had a subtalar fusion of the ipsilateral limb. The treatment was funded by the workers injury compen- 
sation scheme in 58 patients, the remaining 31 were covered by the regular health insurance.

Excluded for this study were patients with septic arthritis of the ankle joint. Six patients (6.3\%) were lost to follow up and were therefore excluded.

\section{Methods}

Via a bilateral approach the malleoli and the joint surfaces were resected. An AO fixator was applied with 4 Steinmann nails. Two Steinmann-nails were inserted with approximately $8 \mathrm{~cm}$ distance in the distal tibia, one in the neck of the talus and one in the dorsal calcaneus. Compression was then applied between talus and distal tibial (Fig. 1 and $2 \mathrm{a}, \mathrm{b}$ ). We aim for a neutral position of the arthrodesis with a maximum of $5^{\circ}$ valgus und slight dorsalisation of the talus.

During the procedure the patients received single shot antibiotic prophylaxis. Postoperatively, subcuta-

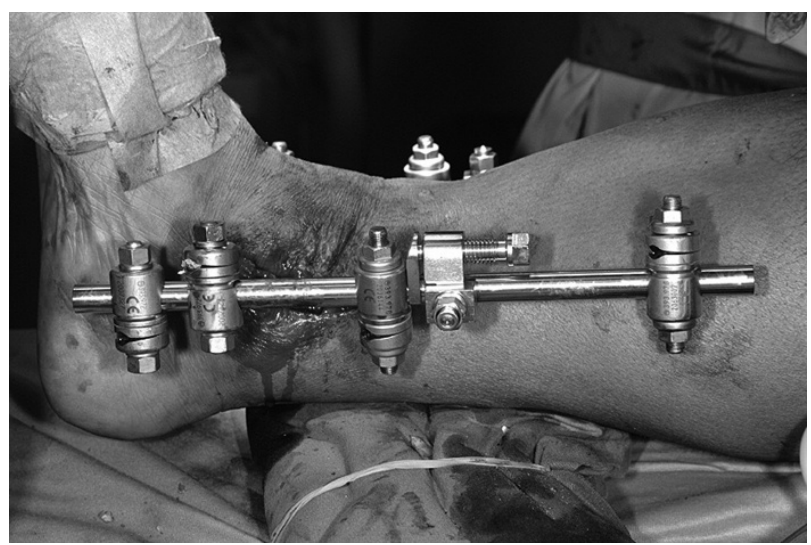

Fig. 1. External fixator applied in a slightly triangular fashion, compression is applied between distal tibial and talar Steinmann-nail. neous low molecular weight heparin was prescribed until full weight bearing was achieved. Partial weight bearing with approximately $10 \mathrm{~kg}$ for 12 weeks followed. Patients were discharged after mean 7.8 days [514]. When bony union of at least 3 cortices was confirmed on radiographs the external fixator was removed and under protection of a walking cast. The weight was increased over a 4 week period. Finally an arthrodesis boot was fitted.

Follow up examination at mean 4.4 years (26-115 months) included a standardised questionnaire and a clinical examination including the criteria of the AOFAS-Score as described by Kitaoka [20] and radiographs. The follow up examination was performed by an examiner that was not involved in the operative care of the patients. The AOFAS score gives scores from 0 to 100 . A score of $90-100$ is judged as an excellent result, 75-89 as good, 60-74 as fair and below 60 as poor.

Statistical analysis included means, variance analysis chis square and T-test with significance testing, p-values $<0.05$ where deemed as significant. The software program WinStat 3.1 (Kalmia Co. Inc.,USA) was used for statistical evaluation.

\section{RESULTS}

In all cases the index procedure was possible although in 2 cases soft tissue contracture meant that a pes equinus position of approximately $15^{\circ}$ was required.

In two cases a further cancellous bone transplant was performed at 6 and 9 weeks for unsatisfactory bony union. After mean 12.3 (8-16) weeks radiographs confirmed satisfactory union and the fixator was removed.

There were no cases of deep vein thrombosis or pulmonary embolism detected in the postoperative period. In 9 cases $(10.1 \%)$ we saw a reversible irritation of the dorsal cutaneous nerve. In 18 cases patients de-

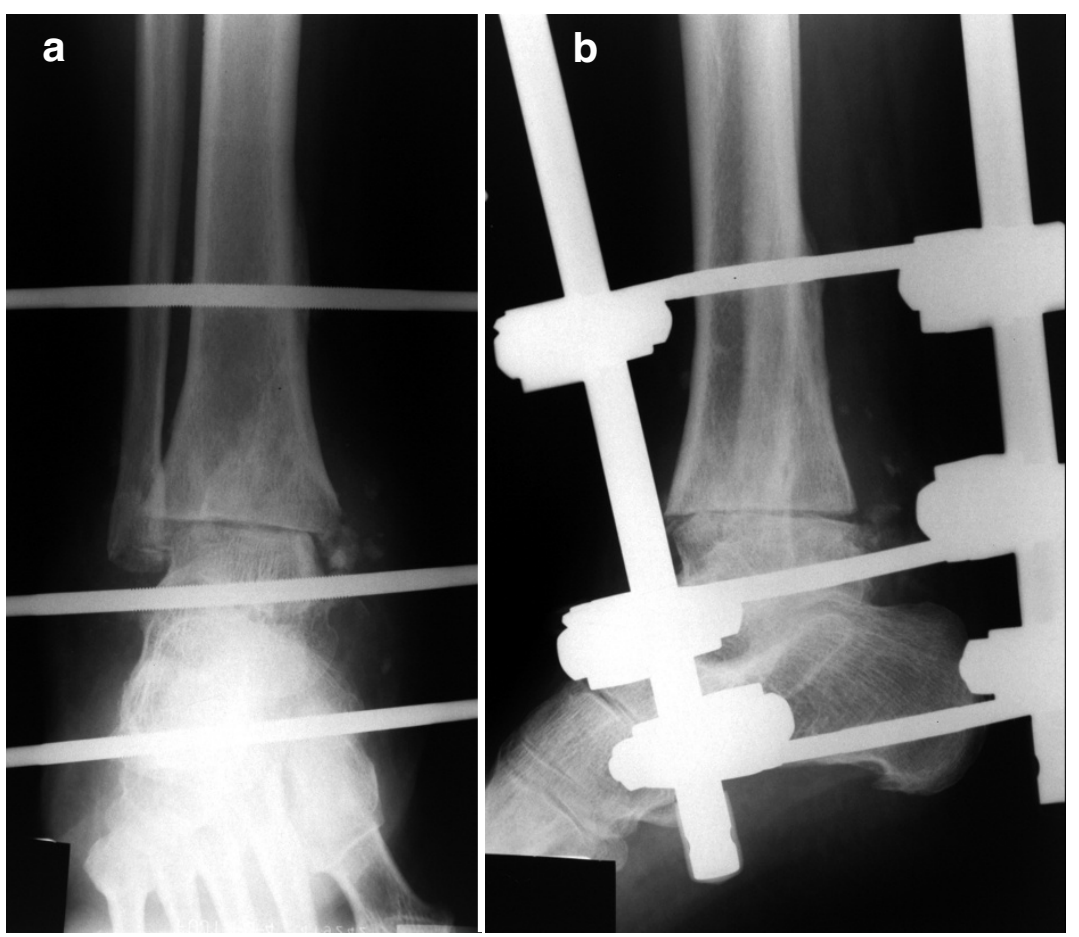

Fig. 2. $a, b$ a.p. and oblique radiograph of the compression arthrodesis. 

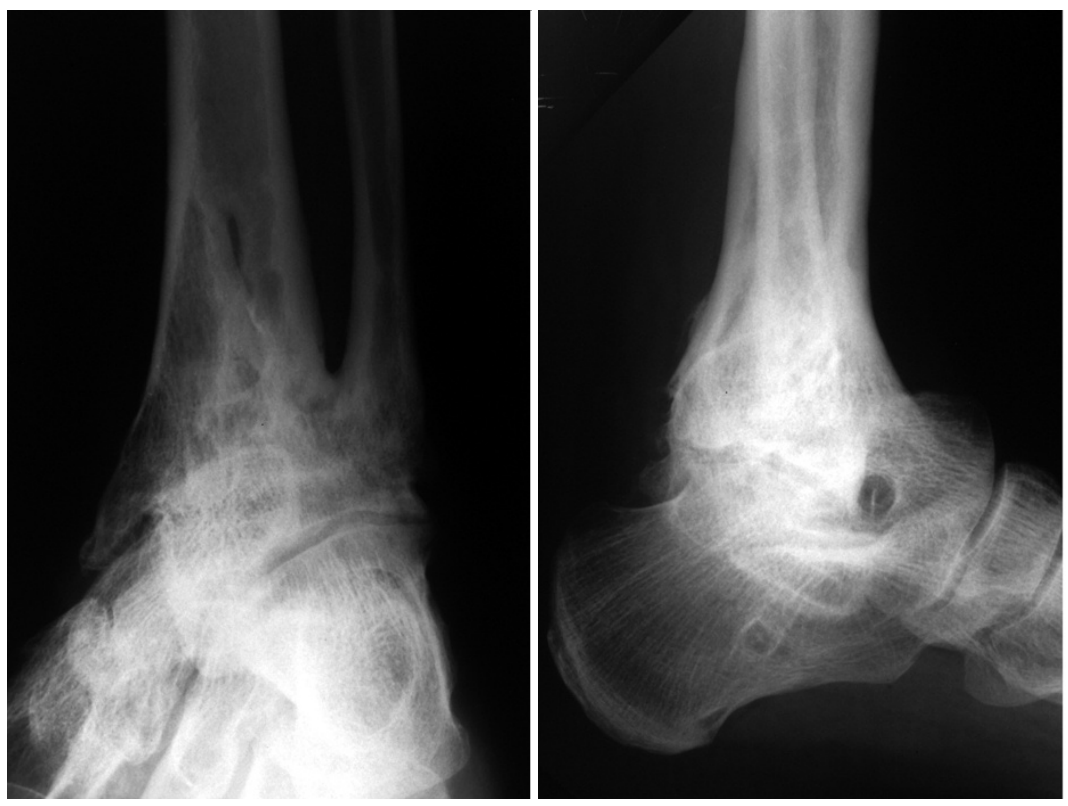

Fig. 3. Radiographs of a 42 year old male patient 98 months after arthrodesis. There are signs of subtalar arthrosis, the Kitaoka score was 62 . veloped a pin tract infection $(20.2 \%)$ which healed under conservative measures. In one case $(1.1 \%)$ a bony infection around a pin site developed making 3 surgical procedures for treatment necessary. One patient suffered a fracture of the tibia at the site of the proximal tibial pin site 5 months after removal of the fixator due to a minor trauma. In 4 patients a non-union of the ankle arthrodesis developed (4.5\%). In one patient a further procedure was successful, one patient $(1.1 \%)$ with a previous Lisfranc amputation and a difficult soft tissue situation at the amputation site opted for a below knee amputation. Two patients refused further surgical intervention and were fitted with orthopaedic boots. A risk factor analysis for development of nonunion showed no significance for the possible risk factors diabetes, nicotine abuse, age and $\mathrm{BMI}>30$.

Overall there were thereby $8(8.9 \%)$ further surgical procedures necessary in this series.

At the follow up examination a mean leg length discrepancy of $-12 \mathrm{~mm}$ ( 0 to $-17 \mathrm{~mm}$ ) was measured. Lower leg circumference difference was measured on average with $-41 \mathrm{~mm}(-5$ to $-110 \mathrm{~mm})$. In 31 cases radiographic signs of arthrosis in the subtalar joint had developed $(35.2 \%)$, two patients had a subtalar fusion between index procedure and follow up (Fig. 3).

The mean AOFAS score (Diagram 1) improved from 20.77 (Std.dev.16.2) to 69.3 at follow up (Std.dev. 21.5, $\mathrm{p}=0.004^{-30}$, T-test). The largest improvements

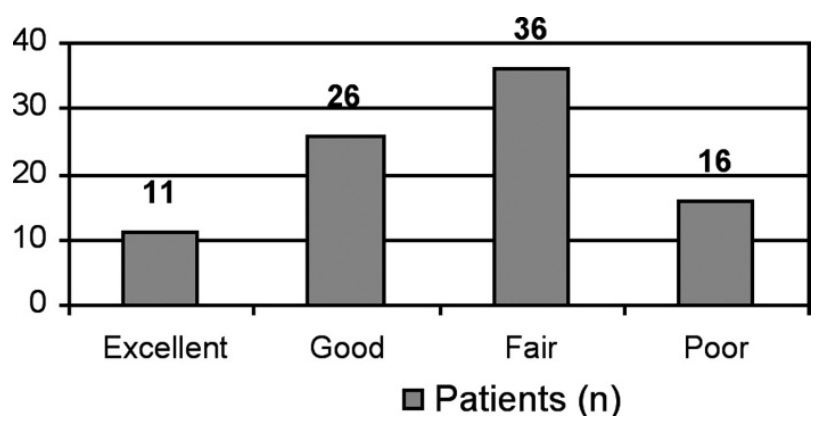

Diagram 1. Grouped results of the AOFAS-score were found regarding to pain and walking distance. Whilst preoperatively only one patient had mild pain, at follow up 54 patients had no or only mild pain. The maximal walking distance improved from mean 675 metres to mean $3245 \mathrm{~m}$ (T-test, $\mathrm{p}<0.025^{-18}$ ).

Statistical analysis of the insurance status showed patients that had an injury related to their occupation to be on average 5 years younger, the difference was statistically not significant (mean 44.8 years vs. 49.8 years; $\mathrm{p}=0.071)$. Also the preoperative AOFAS score showed no statistical difference. There was a statistical difference in the AOFAS score at follow up. Patients insured under a workers injury compensation scheme had a mean score of 63.6 compared to 75.1 for the remaining (T-test, $\mathrm{p}=0.027$ ).

Asked if they would opt for this kind of treatment again, 76 patients $(85 \%)$ would, 5 were undecided and 8 would opt against it.

\section{DiscusSION}

The external compression arthrodesis as described by Charnley [8] was the standard method for a long while. High rates of non union $[11,14,16,24,35]$ led to biomechanical [27, 29, 30, 32, 33] and clinical comparison with internal fixation methods $[6,24]$. The best biomechanical results were achieved with plate or nail osteosynthesis $[2,31]$.

Biomechanical studies showed the Charnley type external fixator to have inferior stability especially regarding rotational forces [31, 36]. Calandruccio [7], Hagen [15] und Berman [3] achieved a significant improvement in stability via a three point fixation using 2 more Steinmann-nails and thereby improved union rates.

With this technique we saw a non-union rate of $4.5 \%$ in our series; this is comparable to internal arthrodesis with non union rates of about $4 \%$ (Table 1 ).

The pinsite infection rate of $20 \%$ is in its rate in accordance with other studies [5, 19, 22, 24, 27, 35, 40] and is in our view one of the main disadvantages of this method as it often requires admission and active 
Table 1. reported non-union rates after internal arthrodesis of the ankle joint.

\begin{tabular}{llll}
\hline Authors & Year & $\begin{array}{l}\text { Non union/ } \\
\text { All Patients }\end{array}$ & Percent \\
\hline Morgan et al. [26] & $(1985)$ & $5 / 101$ & $5 \%$ \\
Breitfuß et al. [5] & $(1989)$ & $0 / 25$ & $0 \%$ \\
Myerson/Quill [29] & $(1990)$ & $1 / 33$ & $3 \%$ \\
Moeckel et al. [24] & $(1990)$ & $2 / 40$ & $5 \%$ \\
Thermann et al. [40] & $(1996)$ & $2 / 28$ & 7.1 \\
Crosby et al. [10] & $(1996)$ & $3 / 42$ & 7.1 \\
Rockett et al. [33] & $(1997)$ & $1 / 14$ & $7.1 \%$ \\
Monroe [25] & $(1999)$ & $2 / 29$ & $6.8 \%$ \\
Buchner/Sabo [6] & $(2003)$ & $1 / 23$ & $4 \%$ \\
All & & $17 / 345$ & $4 \%$ \\
\hline
\end{tabular}

treatment. The rate of necessary revisions for surgical or technical complications was relatively high with 8 $(8.9 \%)$. further surgical procedures. In series treated with internal fixation there are complication rates of up to $10 \%$ reported due to the osteosynthesis material $[33,36,40,41]$, the rates of necessary further procedures including the removal of metalwork is reported between 11 to $22 \%[6,10,33]$.

One patient suffered a pathological fracture at a tibial pin site; this problem also has been reported after internal screw fixation [22]. An arthrodesis site infection is a known problem after internal fixation $[6,14$, $15,24]$, no such complication occurred in our series. The loss of alignment was a known problem of Charnley type external fixation $[5,14,35]$, with a triangular setup of the fixator, no secondary loss of correction occurred.

The surgical techniques for ankle arthrodesis differ, in this series as in others, the destroyed joint surfaces are removed together with subchondral bone [26], others only remove the cartilage with or without drilling of the sclerotic bone [17, 29, 33, 40]. Judging by the results there is no sign that one method is superior to another. Some authors recommend to salvage the medial malleolus $[17,40]$, others always perform arthrodesis under usage of the osteomised distal fibula $[17,21,22,28,35]$. Again our results suggest that this is not necessary, the correction of a deformity might actually be hindered by remaining malleoli [30, 38]. The perfusion of the talus is sometimes quoted as a rationale for salvage of the medial malleolus [17, 40]. We saw no cases of osteonecrosis of the talus in our series.

In studies directly comparing internal and external osteosynthesis methods, the complication rates of external methods are generally reported higher but the clinical results at follow up do not differ significantly $[6,24,40]$. For the AOFAS-Score after internal osteosynthis results between 67 to 76 points are reported $[6,40,12]$, wich is in accordance with the 69.3 we found in our series. Interesting here was the significantly worse outcome after occupational accidens, a fact that has not been reported in the literature. We have no medical explanation for this finding.

\section{CONCLUSION}

Non-union rates and clinical results of resection arthrodesis by triangular external fixation for posttraumatic arthrosis of the ankle joint do not differ to internal fixation methods. The complication rate and the reduced patient comfort reserve this method mainly for infected arthritis and complicated soft tissue situations. Clinical results are worse after accidents covered by a workers compensation scheme.

Conflict of interest statement: There is no conflict of interest to declare.

\section{REFERENCES}

1. Bauer G, Kinzl L. Arthrodesis of the ankle joint. Orthopäde 1996; $25158-65$

2. Berend ME, Glisson RR, Nunley JA. A biomechanical comparison of intramedullary nail and crossed lag screw fixation for tibiotalocalcaneal arthrodesis. Foot Ankle Int. 1997; (18 10) 639 - 43

3. Berman AT, Bosacco SJ, Yanicko DR, Raisis LW. Compression arthrodesis of the ankle by triangular external fixation: An improved technique. Orthopedics 1989; Vol 12/ No 101327 - 30

4. Boobbyer GN. The long-term results of ankle arthrodesis. Acta ortop. Scand. 1981, $52107-10$

5. Breitfuß H, Muhr G, Mönnig B. Fixation or screws in arthrodesis of the upper ankle joint. A retrospective comparison of 76 patients. Unfallchirurg 1989; 92245 - 53

6. Buchner M, Sabo D. External or internal fixation for arthrodesis of the ankle - a comparative study of perioperative and long-term results. Unfallchirurg 2003; 106 $472-77$

7. Balandruccio R. Triangular compression device. Richards Medical Company 1985

8. Charnley J. Compression arthrodesis of the ankle and shoulder. J Bone Joint Surg 1951; Vol 33 B / No 2180 91

9. Cracchiolo A, Cimino WR,Lian G (1992) Arthrodesis of the ankle in patients who have rheumatoid arthritis. J Bone Joint Surg 74A:903-909

10. Crosby LA, Yee TC, Formanek TS, Fitzgibbons TC. Complications following arthroscopic ankle arthrodesis. J Foot Surg 1996; Vol 17 / No 6340 - 42

11. Eingartner C, Volkmann R, Winter E, Weller S. Bone repair in pseudarthrosis after arthrodesis of the upper ankle joint. Akt. Traumatol. 1994; $24155-60$

12. Flückiger G, Weber M. Transfibular Approach for Ankle Arthrodesis. Oper Orthop Traumatol 2005;17:361-79

13. Frey C, Halikus NM,Vu-Rose T, Ebramzadeh E. (1994) A review of ankle arthrodesis: predisposing factors to nonunion.Foot Ankle Int 15:581-584

14. Günter U, Zacher J. Die Pseudarthrose nach Arthrodese - eine Analyse der Indikationen und Methoden bei 64 Sprunggelenken. Orthop.Praxis 2000; 36 / 8490 - 96

15. Hagen RJ. Ankle arthrodesis. Problems and pitfalls. Clin Orthop 1986; $202152-62$

16. Helm R. The results of ankle arthrodesis. J Bone Joint Surg 1990; Vol 72-B / No 1141 - 43

17. Holt ES, Hansen ST, Mayo KA, Sageorzan BJ. Ankle arthrodesis using internal screw fixation. Clin Orthop Rel Res 1991; $26821-28$

18. Kitaoka HB. Salvage of non-union following ankle arthrodesis for failed total ankle arthroplasty. Clin Orthop Rel Res 1991; 26837 - 43

19. Kitaoka HB, Anderson PJ, Morrey BF. Revision of arthrodesis with external fixation for non-union. J Bone Joint Surg 1992; Vol 74-A/ No 81191 - 200 
20. Kitaoka HB,Alexander IJ,Adelaar RS et al. (1994) Clinical rating systems for the anklehindfoot, midfoot, hallux, and lesser toes.Foot Ankle Int 15:349-352

21. Lance EM, Paval A, Fries I, Larsen I, Patterson RL. Arthrodesis of the ankle joint. Clin Orthop Rel Res 1979; $142146-58$

22. Lynch AF, Bourne RB, Rorabeck CH. The long-term results of ankle arthrodesis. J Bone Joint Surg1988; Vol 70B/ No $1113-116$

23. Maurer RC, Cimino WR,Cox CV, Satow GK. (1991) Transarticular cross-screw fixation. A technique of ankle arthrodesis.Clin Orthop 268:56-64

24. Moeckel BH, Patterson BM, Inglis AE, Sculco TP. Ankle arthrodesis: A comparison of internal and external fixation. Clin Orthop Rel Res 1991; 26878 - 83

25. Monroe MT, Beals TC, Manoli A. Clinical outcome of arthrodesis of the ankle using rigid internal fixation with cancellous screws. Foot Ankle Int 1999; Vol 20/ No 4 $227-231$

26. Morgan CD, Henke JA, Bailey RW, Kaufer H, Arbor A. Long-term results of tibotalar arthrodesis. J Bone Joint Surg 1985, Vol 67-A/ No $4546-50$

27. Morrey BF, Wiedeman GP. Complications and long-term results of ankle arthrodeses following trauma. J Bone Joint Surg 1980; Vol 62-A/ No 5777 - 784

28. Müller ME, Allgöwer M, Schneider R, Willenegger (Hrsg.). Manual der Osteosynthese 3.Aufl. Springer, Berlin-Heidelberg-New York 1991

29. Myerson MS, Quill G: Ankle arthrodesis: A comparison of an arthroscopic and an open method of treatment. Clin Orthop Rel Res 1991; 26884 - 95

30. Myerson MS, Miller SD. Salvage after complications of total ankle arthroplasty. Foot Ankle Clin N Am 2002; 7 $191-206$

31. Pilette S, Huk OL, Yahia L, Fowles JV. Comparative biomechanical evalution of the immediate stability of three fixators in arthrodesis of the ankle. Ann Chir 1993; 47 (9) $905-11$

32 Pommer A, David A, Hahn MP, Ostermann PAW, Muhr G. Biomechanical study of the initial stability of various arthrodesis methods for the upper ankle joint. Unfallchirurg 1995; $98535-539$
33. Rockett MS, Zygmunt KH, Brage ME. The use of the synthes $7.3-\mathrm{mm}$ cannulated screw in rearfoot and ankle surgery: A preliminary prospective study. J Foot Ankle Surg 1997; Vol 36/ No 287 - 94

34 Saltzman CL (1999) Total ankle arthroplasty: State of the art. Instr Course Lect 48:263-268

35. Schnettler R, Börner M, Ziegelmüller R, Hinkel E. Arthrodesis of the upper ankle joint Indications, techniques, results. Akt Traumatol 1992; $22251-58$

36. Scranton PE, Fu FH, Brown TD. Ankle arthrodesis: A comparative clinical and biomechanical evalution. Clin Orthop Rel Res 1980; 151234 - 243

37. Stranks GJ,Cecil T, Jeffery IT (1994) Anterior ankle arthrodesis with cross-screw fixation. A dowel graft method used in 20 cases. J Bone Joint Surg 76B:943-946

38. Strohecker T, David A. Prothesis implantation in thr proximal ankle joint - a real alternative in post- traumatic arthrosis? Unfallchirurg 2002; 105619 - 23

39. Stroud CC. Arthroscopic arthrodesis of the ankle, subtalar, and first metatarsophalangeal joint. Foot Ankle Clin N Am 2002; 7135 - 46

40. Thermann H, Hufner T, Roehler A, Tscherne H. Screw arthrodesis of the ankle joint. Technique and outcome. Orthopäde 1996; 25166 - 76

41. Turan I, Wredmark T, Felländer-Tsai L. Arthroscopic ankle arthrodesis in rheumatoid arthritis. Clin Orthop Rel Res 1995; 320110 - 14

42. Wagner H, Pock HG. Screw-fixation in arthrodesis of the ankle joint. Unfallheilkunde 1982; 85280 - 300

Received: September 1, 2007 / Accepted: May 20, 2008

Address for correspondence:

Arndt P. Schulz, MD, MRCS (UK)

Consultant Surgeon Orthopaedics \& Trauma

Study Coordinator

BG Trauma Hospital Hamburg

University Hospital Luebeck

Email: UK-SH@APSCHULZ.DE 